\title{
Lymphovascular Invasion 1
}

National Cancer Institute

\section{Source}

National Cancer Institute. Lymphovascular Invasion 1. NCI Thesaurus. Code C147092.

Lymphovascular invasion is present or identified. (AJCC 8th ed.) 